\title{
1. Introductory remarks about leaders and leadership
}

Leadership is one of the most observed and least understood phenomena on earth.

James McGregor Burns

\section{I.}

Our world is in crisis. In this era of restructuring and reshuffling the world order, when values and priorities are reconsidered, and the globe is becoming truly 'global', there is a desperate need, and demand, for leaders and managers with a perspective that goes beyond parochial, national and even regional boundaries to encompass emerging international urgencies. I call our times The New Common Era because, I feel, it resembles the original one, that of the early Christian world, which encompassed the diverse geographical areas of the Mediterranean basin, Asia Minor and Roman Europe. As in those days, ours are rapidly becoming truly interdependent and interconnected.

The original Common Era related to a time and place that redefined the basis of our civilization and gave it its characteristic Western feel, borrowing and merging the values from Judaeo-Christianity and the Graeco-Roman world. The outcome was the replacement of old Rome by its politico-religious successor, the Catholic Church, that eventually split into the Western (Roman-dominated) lands of Europe and the Eastern theocratic Byzantine Empire. Those initial divisions continued to split and subdivide geographically, ideologically, politically and culturally over the ensuing centuries down to the present day, which is characterized, again, by pluralism and multiculturalism. Subsequently we are reaching a state of new unification as a result of technological advances, economic interdependence and the necessity to share resources. Thus a New Common Era is again upon us promising, as well as threatening, to consume national and regional identities into a world 'melting pot' resulting in a new world order with new political and economic realities. 
The way forward, and our success or failure, will depend on the role that our emergent leaders will be called upon to fulfil. The importance therefore of the choices we make in appointing and following our leaders becomes paramount. A leader in this new Common Era, as in the original one, will have to be able to balance the needs of his specific constituents to those of the world at large and to walk the fine line between regionalism (nationalism if you will) and internationalism since our interdependence gets progressively deeper. Consider the example of the recent European financial crisis. As the Northern economies are striving to remain stable, they need to fork out part of their wealth towards their needy Southern partners in order to maintain their (pseudo) political and financial union. A similar situation arose a couple of centuries ago between the northern and the southern United States when the visionary leadership of the American founding fathers and subsequent presidents helped glue that union together. ${ }^{1}$ The role of leaders, then and now, remains central in determining the outcomes that follow.

Nowadays the world is morphing into regional spheres of political and economic interests. The Americas, the European Union, the Organization of the Petroleum Exporting Countries (OPEC) countries, and the former Soviet Republics are but a few examples. Even between such regions, however, there is an increasing tendency for collaboration and co-existence, due partly to an appreciation of the world's limited natural resources and the imperative for developing sustainable ones. Such tendencies are contrasted with the feeling, and evidence, that different world ideologies and regions are on an inevitable course of collision and that disaster lurks maliciously in our future.

Whether we co-exist or co-destruct, our future hangs on threads and strings tangled by people we appoint to be in charge of our affairs. Can we collectively take charge and guide our leaders to take wise decisions or are we desperately dependent on their own initiatives and understanding of what course of action must be taken? We can begin to answer this question with an attempt to understand the phenomenon of leadership, the characteristics of successful leaders, and their relationship to followers.

1 Following the end of American Civil War the North, under the guidance of Republicans, set up reconstruction governments in many Southern states in order to help them rejoin the Union and advance politically, economically and socially (Foner 1990). 
II.

It was said that history is written by the masses and individuals merely succumb to the will of the multitude. Such an idea may be psychologically appealing to most of us because it provides support to our egocentric predispositions, as well as meaning, in what sometimes appears to be a purposeless state of being. It constitutes a cosy and comfortable feeling of worthiness and importance, not to mention collective participation in progress. The alternative view of course is that history is driven by a few individuals, or gifted leaders who, by the mere radiance of their character, their personality, and the timing of their appearance, determine the choices and fates of their societies. The former paradigm was the essential factor considered by the Marxist ideology in prophesizing the ultimate victory of the proletariat against another, albeit smaller multitude, that of the bourgeoisie. The latter paradigm, which holds that individuals, and not the masses, make the difference, provides an explanation for different groups of people reaching greatness at certain historical times. Such an example would be the well-known golden age of Athens ushered in after the defeat of the Persians; Pericles is thought to have skilfully led the ancient Athenians into an era of unparalleled creativity, political progress, and artistic output, that has continuously influenced western civilization, and beyond, ever since (Kagan 1998). He swayed his co-citizens into accepting pre-conceived notions that had already fermented in his mind, with such skill in rhetoric, that they were proudly adopted as their own democratically formed decisions.

Such skill in leadership, according to Stephen Denning (2007), requires, first and foremost, the ability to communicate the type of language that 'feels fresh and inviting, energizing and invigorating, challenging and yet enjoyable, lively, spirited, and fun, as when equals are talking to equals'. A similar notion was put forth in antiquity by Aristotle in his Politics (2001) when he spoke about government, which he considered to be "not like the rule of a shepherd over his sheep, but the rule of equals over equals'. Of course, equals are not talking to equals since in every relationship automatically there will be a leader and a follower or followers. In fact, 'leader-follower structure emerges spontaneously even when groups set out to be leaderless' (Bass 1954). The latter however may confer leadership qualities onto the former, and can withdraw it as they see fit; thus, Foucault's (1978) saying that in a certain way, one is always the ruler and the ruled', becomes instructive.

The skill of a leader should ensure that he appears, and persuades followers, that their association is a legitimate, if not an egalitarian one. 
Leadership therefore can be seen as a 'process of influence', which nevertheless induces folk ideas that appear to emphasize persuasion rather than coercion as its main strategy (Hogan, Curphy, and Hogan 1994). Therefore the role of language in bringing about persuasion that enhances political action assumes clear significance. In that respect, language is a fundamental aspect of the leadership process, shaped by both leaders and followers as they interact (Bligh, Kohles, and Meindl 2004). According to Warren Bennis (2003), 'Leadership is quite simple. It is the way great leaders communicate that sets them apart'. The role language plays in the formation of leader-follower relationships will be central to this book.

The question about which factor is important in driving society forward, the crowd or the individual leader, is not new and has been the subject of hotly debated arguments throughout history. This basic but ever-present question will be the topic of this diatribe approached from a bio-psycho-social perspective. The bio- part will refer to genetics and evolutionary perspectives regarding the phenomenon of leadership; the psycho- part will refer to personality traits and putative character pathologies that leaders possess; and the social part will refer to the cultural context in which leaders emerge.

In other words, we will attempt to answer whether such phenomena as democracy and new religious movements came about as a collective culmination of social progress, or as the guided process of charismatic leaders. Were Christianity, Islam, or the Magna Carta, to use but a few examples, steps forward of a society at large, or brainchildren of prophets and able civil magistrates? And if we assume that history is written by few special individuals, what attributes should they have in order to carry out their leadership potential? Do they represent the average individual in their society, who just happened to be at the right place at the right time, or do they come with some unusual and exceptional qualifications? Obviously, their presence needs to be signalled out to the people who will become followers and the followers themselves must be attuned to their potential leader's presence; Halpern and Lubar (2003) discuss this presence, which they define as 'the ability to connect authentically with the thoughts and feelings of others'. In other words, to use such language and mannerisms that will signify to others that a leader is speaking. To reiterate, language, that unique human characteristic, will be central in the discussions that follow in this book as we explore the characteristics that leaders should have in order to lead effectively.

As we said, the above questions are hardly novel ones; many historians, social scientists, philosophers, and other students of humanity have pondered these very issues. And, as is usually the case, there are 
competing theories and explanations, opposing views, and middle of the road positions. Karl Marx, for example, as a result of his intense preoccupation with class struggles and economic forces in society, had a tendency to ignore the individual, in favour of the masses. As he put it (1978 [1857-58], p. 247), 'society does not consist of individuals, but expresses the sum of interrelations, the relations within which these individuals stand.' On a different occasion (1978 [1845], p. 145) he wrote that 'the human essence is no abstraction in each single individual. In its reality it is the ensemble of the social relations.' Economic forces, according to this paradigm, are driving society, as well as history at large, and they are embodied in the multitude leaving little room for individual action let alone choice. Marx is therefore a constructionist in his views; the constructionist paradigm holds that reality, and therefore the necessity of leadership, is the product of human constructs, which attain meaning through social, political, and other culturally-defined interactions (Hickman and Couto 2006). In contrast, essentialists hold that the world, and reality, exist in their own right, and individuals perceive them through their senses (Rosenblum and Travis 2008). According to the constructionist paradigm, the notion of the so-called 'great men of history' is nothing but a misconception, an illusion of nineteenth-century romantic thinkers. Engels proceeds even further in stating, 'that such and such a man and precisely that man arises at a particular time in a particular country is, of course, pure chance. But cut him out and there will be a demand for a substitute, and this substitute will be found ... If a Napoleon had been lacking, another would have filled the place' (Engels 1978 [1894], p. 767-8).

Contrast these views with those opposing ones of Thomas Carlyle (1972 [1840], p. 101) who wrote that:

Universal history, the history of what man has accomplished in this world, is at the bottom the history of the Great Men who have worked here. They were the leaders of men ... the modelers, patterns, and in wide sense creators, of whatever the general mass of men contrived to do or to attain; all things that we see standing accomplished in the world are properly the outer material results, the practical realization and embodiment of Thoughts that dwelt in the Great Men sent into the world: the soul of the whole world's history, it may justly be considered, were the history of these.

Unmistakable nineteenth-century prose, that nonetheless makes the point quite clear; the history of the world is the history of great individuals. Great events occurred because, and precisely because, these men willed them. 
Similarly, Sidney Hook (1943) considers an individual leader's style and personality as important factors that are causal on the development of historical events. Certainly, and he makes the argument, the course of the Bolshevik revolution was influenced by Lenin's leadership and would have turned out differently if another man had taken his place; we can make the same claim for Alexander the Great and Macedonia, Napoleon and France, or Hitler and Germany. These personalities emerged within certain 'situations and conditions' and brought about remarkable results. Therefore, and as Chiari (1975) argues about social phenomena 'there is always a residuum of uniqueness which does not fit the abstractions and generalizations in which the scientist would like to enclose it'.

Similar to Great Man theory, trait theory proposed that leadership depended on the personal qualities of the leader, but unlike the Great Man theory, it did not necessarily assume that leadership resided solely within the grasp of a few heroic men (Terman 1904). On the other hand, and following attempts to portray a notable leader's 'typical' profile, House and Aditya (1997) concluded, that 'there were few, if any, universal traits associated with effective leadership ... [and] that the search for universal traits was futile'. We will argue in the rest of this book that there are, indeed, social and biological traits (such as certain psychopathologic traits including paranoia), that fit the bill of the personality of leadership. Genetic studies have begun to tilt the pendulum towards the direction of biological determinism with, perhaps, the identification of putative leadership genes (De Neve et al. 2013).

Tucker (1981) reminds us that the argument is as old as civilization. He contrasts Socrates, the mentor, who focused on the power of the city, the collective citizens of Athens, the Demos, and therefore de-emphasized the individual, with his pupil Plato, whose notion of the philosopher king proposes that man is in charge of his destiny and determines his political development. Therefore, even close associates, teachers and pupils, have taken differing approaches to the issue.

Conciliatory views have also been proposed. William McKinley Runyan (1988a) is critical of both extremes and tries to reconcile them in a middle-of-the-road, reciprocal approach:

It is, unquestionably, simplistic to claim that 'History=Biography' or that history can be reduced to nothing more than the aggregation of individual biographies, since this leaves out the impact of ecological and demographic factors, ignores the evolution of economic, political, religious, educational, and other institutions, and neglects the complex interactions between institutions and social groups. It is, however, equally reductionistic to claim that an understanding of individual persons and their psychological processes has 
nothing to contribute to an analysis of the history of groups, social movements, institutions and nations. Only a dogmatic reductionism would maintain that the personality and life of Hitler had nothing to do with the course of World War II; of Lenin, with the Russian revolution; of Gandhi, with India's struggle with the British; or of Martin Luther King, Jr., with the civil rights movement.

Obviously history is neither biology nor pure economics, and world events need to be understood within their temporal, socio-political, cultural, and biological contexts in order to make sense out of them, as well as interpret them through a meaningful exegesis. Our concern here is with the overall 'tendencies' within these contexts and the source of influence that governs them; society at large, the individual leader, or a balanced dyadic relationship? Post (2004) states precisely this point, and expresses current thinking which sees the leader in context, not in isolation from his group, neither as an undifferentiated member. Contingency theorists (Fiedler 1972), also focus on the context of leader emergence as well as the leader's personal characteristics. Contemporary thinking considers leadership a process that can be learned and coached, borrowing from behavioural and cognitive psychology; leadership style and such distinctions as task-oriented (Stogdill 1957) versus peopleoriented (Bales and Slater 1945) leaders emerge as important factors. In addition, internal processes of both leaders and followers, as affected by cultural, historical, but also individual psychological factors, need to be taken into account (Ayman and Chemers 1983). Even more recently, moral theories of leadership, and leader-follower relationships, proposed a common cause, and a contract between equal parties, to attain it (Burns 1978). The concepts of servant, citizen, and transformational leadership, grew out of these moral theories (Greenleaf 1977, Burns 1978, Couto 1992). We will discuss these issues further on in subsequent parts of this book.

III.

Leadership-followership patterns, according to some scientists, may have emerged in social species, including humans, in order to solve coordination problems and they represent social strategies that have been selected for by virtue of their success in fostering collective action (Van Vugt 2006). They therefore contribute to the success of groups in addition to that of individuals; at the group level, followers might fare better than individuals in groups without leaders or poorly functioning leaders (Van Vugt 2006). Leadership, then, has emerged in human 
evolutionary history, because between-group selection pressures were stronger than within-group selection pressures (Sober and Wilson 1998). ${ }^{2}$

All in all, however, it is the appearance of the phenomenon of leadership that is the driving force behind change, accomplishment, and fulfilment. Whether it is the product of a 'lone ranger' type of leader or the result of a social consensus, it is manifested as 'a function of the group', beyond which it is only '[a] realm of the potential' (Green 2006). Michael Harvey (2006) also reminds us of the ancient Greeks (Aristotle) who knew that "we are really social animals who make sense of the world together. No man is an island of thought.' Similarly, Giddens (1976) argues that 'the production and reproduction of society ... has to be treated as a skilled performance of its members'.

We will argue subsequently that culture moulds the individual's personality, which, in turn, moulds culture. By the same token, it can be said that groups mould (and choose) their leaders who, in turn, mould the very groups that select them in a reciprocal and mutually dependent, symbiotic way. This is analogous, as we will see later on, to the notion of evolutionary brain development that produced that unique organ and set humanity apart from the rest of the animal kingdom; tools enhanced the progressive sophistication of the human brain, which, in turn, produced more complex tools; these in turn produced more sophisticated brains; and on, and on ...

The leader in context, as stated above, is the current way to view leadership in general, borrowing notions from cultural anthropology but taking into account its biological aspects as well. What's important to understand, however, is that within the right context, it is the individual leader who shapes his group's actions. As Bennis (2003) states, 'just as no great painting has ever been created by a committee, no great vision has ever emerged from the herd'. Stephen Denning (2007) speaks of transformational leaders who:

Change the world by generating enduring enthusiasm for a common cause. They present innovative solutions to solve significant problems. They catalyse shifts in people's values and ideologies. They demonstrate willingness to sacrifice personal interests when necessary. They help others get through critical moments of crisis. They inspire people to want to change, so that positive energy sustains the change over time.

2 This argument resembles the group selection logic for the evolution of altruism (Sober and Wilson 1998). 
Personality or trait models assume the presence of distinct personality traits reliably distinguishing leaders from non-leaders, whereas situational or state theories of leadership emphasize the importance of the decision situation in determining who emerges as a leader (Van Vugt 2006).

Whichever model one adheres to, the unavoidably obvious question that follows is how they bring about this transformation. Communication skills constitute the critical tool to get the message across. Language, then, becomes the sole significant means by which a leader can attract his followers. Such communication may be oral, written, or electronically conveyed, as President Barack Obama and his team have recently showed by the flood of electronic mailings that have been sent to rally support for health care reform and other issues.

In order to delve further into the above questions we need to briefly digress into the history of man and his cultures, which, for our purposes, may be understood as the by-product of a genetic endowment that determines behaviour in ways more subtle than obvious. In other words, we will consider human behaviour, and human achievement, as a biologically determined phenomenon that obeys all the laws and rules by which living organisms exist. In the case of humans, biology produced two characteristics that have changed our terms of existence in remarkable ways; these two characteristics, of course, are language and culture. Both, we will argue, are biologically determined and are associated with other qualities when they create an environment suitable for leaders to ascend. After all, recent evidence has tilted the scale in favour of nature via nurture as far as human behaviour is concerned (Ridley 2003). But to make our argument convincing, we must consider social and behavioural phenomena that have remained constant (universal) across cultures and through time, thus lending credence to putative genetic causations. My own biological biases will become rather obvious on many occasions throughout this book. I hope to convince my readers as well.

Among the few cultural universals that one can find in the study of human behaviour is what philosopher Adam Smith (1776) called our strife to continually improve the means of our subsistence. Be it the primitive man's attempt to sharpen his arrows (thus procuring a better yield of game), or modern times' ever increasing efforts to produce sustainable energy resources, the ultimate goal is to improve our conditions of living. This phenomenon has been going on since the dawn of history and, assuming that we somehow manage to avoid annihilating ourselves in the process, will most likely go on forever. The consequence of this fact is a constantly changing social, technological and political milieu, which itself issues from the constant struggle to improve our 
lives. In other words, a cultural constant induces a continuous process that is none other than change. No society has remained immutable for ever so that 'change and continuity is an endless cycle' (Harvey 2006). Even among the most traditional cultures, change is ever-present, albeit very slow. The ubiquitous nature of this phenomenon supports the idea that, at its basic level, it is biologically determined. 'Nothing endures but change' was written by Heraclitus (Barnes 1982).

What, then, drives this inescapably constant change in our historical existence, appears to be hard-wired into our genetic programming, resulting in an almost deterministic (and futile) nature that was shaped millennia ago to ensure our survival as a species. Our beliefs and behaviour (that constellation of our attitudes about ourselves and our environs and the way we act upon them), may leave fewer personal liberties of choice than our anthropocentric views of reality are comfortable with. Recently conducted research (Custers and Aarts 2010) suggests that our choices and actions are controlled by our brain on a subconscious level long before they manifest behaviourally; this is the end result of brain evolution and sheds doubts on the existence of free will. Consequently, our choices and actions may owe more to our primordial milieu than our current (but ever-changing) concepts of social norms. Darwinian evolution and its underlying mechanism of natural selection have long ago cemented the explanations of these actions and reactions to the various vicissitudes of our daily lives. They have also set the limits into which the ranges of observable human behaviours are to be found given the finishing touches of nurture. Mat Ridley (2003) says that 'culture will often reflect human nature rather than affect it'.

A basic function of culture is to set limits on behaviour by establishing norms. Normal and abnormal behaviour may be seen as the ends of a continuum that are statistically clustered around a mean, with standard deviations setting the limits of tolerance outside of which our actions are deemed unacceptable or, at the very least, strange. Behaviours closely approaching this mean are considered 'normal' whereas the farther away they get from it, the more intolerantly the social group reacts towards them. Each group of people establishes its own set of values that determine which type of behaviours are acceptable; thus they reinforce a clustering of normal behaviours around their statistical average and increase their probability of occurrence. Throughout history one can find numerous examples of such intolerance and the attempts of society at large to contain that which was thought of as deviant. Medieval society, to use but one well-known example, dramatically witnessed such intolerance in the infamous institution of the Inquisition, which ran for the better part of 600 years, and sought to protect Christian orthodoxy from 
all false dogmas by such means as persuasion, torture, and the burning stake! Moreover, when different cultural groups meet, the more diverse is their behaviour, the more likely their instinctual clash will be. The point was poignantly illustrated by Samuel Huntington (2002) in his much acclaimed and highly controversial book The Clash of Civilizations, in which he argues that different world ideologies are on an inevitable collision course, with destructive consequences. Is the world currently becoming polarized along religious lines? Only time will tell. However, there is undeniable evidence that such a development is currently taking shape and peoples are siding with one or the other camp, not only figuratively but literally as well. Recent world events, realignment of alliances and toppling of old-world establishments, are all in the making and necessitate a deeper understanding of human leadership and its relationships with followers, since this is the level at which such change occurs.

Culture, the most immutable universal phenomenon of human behaviour, provides the vehicle through which those characteristics that set us apart from other mammals are formulated and developed. Humans, write Leakey and Lewin (1992), 'become human through intense learning - not just of survival in the practical worlds, but of customs and social mores, kinship and social laws. In other words: culture. Culture can be said to be the human adaptation'. Social organization is not of course only privy to humans; birds and bees, ants and fish, amphibians and primates, all form and exhibit complex systems of behaviour, pecking orders, and survival strategies. They do not, however, record their history, agonize about their future, or undergo existential crises. Moreover, their amazing and remarkable patterns of behaviour are immutable from one generation to the next, because they are hardwired into their DNA. Human-like attributes in their behaviour are just the result of evolution. For example they 'have genes for altruism, and those genes have been selected in the evolution of many creatures because of the advantage they confer for the continuing survival of the species' (Lewis 1984). Birds that fly south for the winter ensure their survival but this process is accomplished instinctively and automatically through the actions of their genes at critical climactic moments year after year; these birds could not decide one winter to devise the means by which to produce enough heat up north and stay put. It takes the long and slow process of natural selection to favour certain mutations and bring about change. ${ }^{3}$ But by then we are

\footnotetext{
3 This change may be phenotypic and/or behavioural.
} 
dealing with an altogether new and different species which many times bears little phenomenological resemblance to its progenitor.

Homo sapiens (our scientific name which means, perhaps euphemistically, wise man) on the other hand, appears to have diversified his behaviour, adapted to widely varied environments, developed a plethora of tongues and ideologies, and modified his social behaviour with each successive generation; all of this was accomplished in the short time span of his existence that amounts roughly to 50 millennia. Perhaps it is our genomic makeup that programmed us for such unprecedented behavioural diversity, and it would not be unreasonable to assume that this genetic background has evolved precisely to allow behavioural diversification as an ultimate aid to survival. Let me quote Leakey and Lewin again:

Homo sapiens is a cultural creature, to an extent and in a manner unmatched by any other species. This extra dimension of behaviour essentially creates another world, one that may be constantly reshaped. The generation-togeneration transmission of ideas and knowledge means that we all take part in a cumulative expression of our species. Our view of the world, and the material trappings we enjoy in it, depend in a very direct way on what was done one generation back, a hundred generations back. Today, we are the beneficiaries of our distant ancestors in a way not experienced by any other species.

That, in turn, may be the necessary precondition to keep us on this planet. And yet, even though we have been subdivided into different races in response to the environments that nurtured us, we remain a single species. This fact supports the idea that our behavioural diversity is actually a derivative of genetic programming and natural selection. Examples of cultural universals, such as language and culture, must have entered our genes prior to, or just simultaneously, to our division and break off from our hominid (human-like) relatives. Writing about Man and his culture, de Duve (2010) states that 'Unlike other living species, [men] have not achieved their successes by developing appropriate physical adaptations; they have done it with their intelligence.' Moreover, he also asserts that 'we are indeed, of all living beings on Earth, the only ones that are not slavishly subject to natural selection. Thanks to our superior brains, we have the ability to look into the future and to reason, decide, and act in the light of our predictions and expectations, even against our immediate interest, if need be, and for the benefit of a later good'. The value of delayed gratification is hammered into the brains of schoolchildren and students in order to induce them to forgo many options for immediately available types of fun, so that they can reap 
greater satisfaction later on. Most religions promise greater goods in the afterlife as a counterbalance to suffering in this life.

Culture, therefore, may be thought of as that adaptive dimension that has allowed man to become the dominant species on earth. Culture also gave us our identity, language, and those social characteristics that define who we are and where we belong. Culture, in this sense, can be thought of as the ultimate product of human evolution that defines not only who we are, but what we may one day become. It was written that 'in the process of natural selection, then, any device that can insert a higher proportion of certain genes into subsequent generations will come to characterize the species' (Wilson 1975). Humans are characterized by the genetic capacity to produce culture. It is the ultimate tool we have in our constant struggle against the ever-present destructive force of nature, a force physicists call entropy. The ubiquitous process of entropy threatens to consume us if left unchecked. Let's examine it closer.

When the universe was formed about 10 billion years ago, it consisted of a primordial mass that contained all of the elements that make it up today. A terrific explosion took place that is now known as the Big Bang and initiated a continuing expansion that is occurring to this very day. ${ }^{4}$ Throughout the millennia, the heavenly bodies appeared; the stars, planets, and galaxies as we know them today. As a consequence of this continuing expansion, the galaxies and other heavenly bodies keep moving away from each other resulting in a condition of ever-increasing disorder. This universal disorder is called entropy and, as far as scientists can discern, it is constantly increasing and applies to everything in the universe. Culture is man's attempt to counteract it. Culture, in this respect, may be considered the end result of a long evolutionary process that began millennia ago, and is the ultimate tool to aid in our survival. According to Andrew McClary (1975):

Entropy, the obstinate tendency for matter and energy to spread out into even distribution in the environment, seems a characteristic of both the living and nonliving. Is there no way to avoid entropy? If there is, it will probably be found in that product of human evolution we call culture. For it is basic to the character of life, and man in particular, to wage an endless war on entropy.

4 Physicist Stephen Hawking (1988) has called this explosion a singularity because, in the life of this universe, it occurred only once. The study of what happened from that point in time onward, some people consider to fall into the realm of science; whereas what 'happened' before, that of theology. 
An example that is closer to home, and illustrates entropy clearer, is the situation in a 'normal' adolescent's bedroom. No matter how orderly it may get after a visit by the housekeeper, in a matter of days (if not hours), it becomes a place of disorder. Entropy, then, is universal change on a grand scale. Societal change can be thought of as entropy on a smaller, more restricted scale, and leaders, according to Bennis (2003), thrive on it since it lets their true colours come through; in other words, they manage it masterfully well since it provides them with a chance to deal with it head on and, through it, channel their energies into forming new realities for their societies. They break away from what Alexis de Tocqueville described when he wrote about democracy in America: 'I am tempted to believe that what we call necessary institutions are no more than institutions to which we have become accustomed. In matters of social constitution, the field of possibilities is much more extensive than men living in their various societies are ready to imagine'. Leaders become leaders precisely because they have the capacity to imagine those other possibilities and guide their people there. Michael Harvey (2006) writes that 'Leadership draws on who we are, but it also shapes what we might be - a kind of alchemy of souls that can produce both Lincoln's "better angels of our nature" and Hitler's willing executioners'. To attain such imagined worlds, however, a leader must understand what Kurt Lewin (1951) calls, 'the totality of coexisting facts which are conceived as mutually interdependent', weigh all the possibilities, and chart a due course of action. The outcome will determine the greatness, or not, of the leader.

IV.

It is not the purpose of this book to discuss the theory of evolution in great detail, but a basic understanding of its premises is needed in order to follow the rationale of the arguments that will be presented later on. This is important because, as William McKinley Runyan (1988b) wrote, 'An evolutionary perspective directs attention to the interaction among biological evolution, the development of psychological structures and processes, and growth and change in sociocultural systems.' This triad of perspectives is my approach to the phenomenon of leadership.

Evolution is probably the most misunderstood theory that was ever put forward. It does not, as popular belief holds, propose that we evolved from the apes. It does suggest that we and the apes have a remote common ancestor, which is quite a different concept. But let's take things from the beginning. Given the presence of oxygen, nitrogen, hydrogen, 
carbon, water, sunlight and time, life evolved in the primordial seas in simple forms that gradually became more complex. The change occurred secondary to the everlasting need of living organisms to adapt to an ever-changing physical environment. One necessary ingredient was the spontaneous occurrence of mutations, small genetic alterations that brought about structural and behavioural changes in an organism. Most of these accidental changes were actually deleterious and incompatible with survival or resulted in disease. Every so often, however, these changes conferred such characteristics to an organism that actually helped it survive better in the world. Having a better chance to survive meant that this organism had also a better chance to produce offspring that would also bear those changes and reproduce more adapted individuals. Given enough time, the animals with the new characteristics might become the majority whereas the rest became extinct. Thus, a new life form evolved. Recently, a gene known as FOXP2 was identified that is present in many animal species; a mutant form of this gene is somehow associated with the development of language in humans (Enard et al. 2002). ${ }^{5}$ It was so successful in conferring survival capabilities on humans, that it has replaced all previous forms of it, which might have been previously considered to be the normal state. This 'aberration' then gave rise to a new successful species by allowing a more efficient type of communication. Environmental pressures 'select' different mutations that enhance survivability and reproduction. A fine gradation is often observed in the characteristics of a species as it adapts to gradually differing surroundings. As Darwin (1859) himself observes:

I have stated, that in the thirteen species of ground-finches [in the Galapagos Islands], a nearly perfect gradation may be traced, from a beak extraordinarily thick, to one so fine, that it may be compared to that of a warbler. I very much suspect that certain members of the series are confined to different islands; therefore, if the collection had been made on any one island, it would not have presented so perfect a gradation. It is clear, that if several islands have each their peculiar species of the same genera, when these are placed together, they will have a wide range of character.

An evolutionary analysis asserts that there should be benefits associated with a particular trait or behaviour to evolve through natural selection (Betzig 1986, Schmitt and Pilcher 2004). In summary, then, two basic factors are necessary for evolution to occur; spontaneous mutations

5 The same author has recently reported (Enard et al. 2009) that the humanized form of this gene, transjected into mice, alters the type of squeaks that mice produce. 
(producing inter-species variations), and environmental pressures that select them out of other alternatives. ${ }^{6}$ This process is known as natural selection. It works as the environment changes so that the organisms that evolve are well suited and adapted to these changes. Climactic changes are usually what we mean as we talk about environmental pressures. As Leakey and Lewin (1992) write:

Such climactic changes break up habitats, and may drive pulses of extinction throughout the plant and animal worlds. But they may also cause speciation, the development of new species from isolated populations, adapting to new conditions.

One may not help wonder what will result from the recent environmental (climactic) changes that the Earth is going through, as far as humans and other organisms are concerned. De Duve (2010), in discussing our options to save our habitats, hopes that 'with increasing awareness of the disaster we are facing if we do not change course, future initiatives could meet with greater success'. Such initiatives of course will have to come about by the leaders we will choose and their personality traits will be of paramount importance in order to allow them, and us, to make the necessary and imperative decisions, even against our immediate interests, for the benefit of all humanity, the planet, and the rest of living organisms. The main thesis of this book is that to be successful, a leader must have a degree of paranoia in his personality. If a healthy dose of paranoia or other psychological trait is needed in order to accomplish this, then so be it. Subsequent chapters hopefully will help to alert readers in the choices we all make for our leaders and our future. US Republican resistance in bringing about the necessary changes in order to ensure our future in a clean environment, may be seen as an example of paranoia against too much and too fast a change brought about by what they consider to be leftist liberals.

One should not erroneously think that mutations are determined $a$ priori or that they occur in a teleological (that is, towards a specific goal) fashion. They just occur by chance and occasionally they happen to be advantageous to an organism. ${ }^{7}$ A rough sequence of organismal appearance on Earth is as follows; from single-celled (that is, amoebae) to

6 As biologists like to refer to them, Darwinian Theory comprises of two basic premises; that of continuing change and that of natural selection.

7 Alternatively, a religiously inclined person might see 'the hand of God' in this occurrence and many theologians have argued that, if evolution is true, then it must be guided by divine intervention. Even the Scriptures however, hint at 
multiple-celled organisms; from the water to marshes to land; from fish to amphibians to reptiles; the latter gave rise to both birds and mammals. ${ }^{8}$ All evidence suggests that life initially developed in the sea. Even today, animals, including man, are made up mostly of water, and in fact, of saltwater, reflecting the primordial environment that surrounded our ancestral life forms. ${ }^{9}$

An interplay between the human brain, culture, tools, and language appears to have set the stage for the evolution of large convoluted brains, especially on the surface (what we colloquially call the grey matter), and even more so its frontal part known as the forebrain ${ }^{10}$ that sub-serves such things as language, personality, and social skills. Those characteristics, in other words, that set us apart from other animals and made us human. Of these, language appears to have had the lion's share in importance. As Leakey and Lewin (1993) put it:

When we contemplate our origins, we quickly come to focus on language. Objective standards for our uniqueness as a species, such as our bipedality and our relatively enormous brain, are easy to measure. But in many ways it is language that makes us feel human. Ours is a world of words. Our thoughts, our world of imagination, our communication, our richly fashioned culture all are woven on the loom of language. Language can conjure up images in our minds. Language can stir our emotions - sadness, happiness, love, hatred. Through language we can express individuality or demand collective loyalty. Quite simply, language is our medium.

evolution in the famous story of Noah who, having exhibited the 'right' characteristics, was able, following divine providence, to survive the cataclysmic environmental change of the flood, and inaugurate a new generation of a different - dare I say evolved? - human race. Matt Ridley (2003) on the other hand uses the term Gene Organizing Device - GOD - to describe the process.

8 Interestingly, a similar sequence is presented in the Bible and has been taught by theologians and Sunday school teachers for centuries. Therefore, the recently observed animosity between the so-called creationists and the evolutionists may, ironically, be more the result of misunderstanding than an actual conceptual difference.

9 In the popular TV science fiction series Star Trek: The Next Generation, Captain Picard and his crew encounter a crystalline - thus perfectly symmetrical - life form on a distant planet, which, after they managed to communicate with each other, described humans as 'ugly bags of mostly water!'

10 Telencephalon, meaning end-brain, is the scientific term used to describe this part of the anatomy of the nervous system to emphasize its relatively recent development in evolution and the - almost teleological - fact that it is found only in humans. 
Chomsky (1965) proposed in the 1960s that the brain possesses a language acquisition device that is uniquely human and operates through similar mechanisms in people of all languages, and sub-serves the rules of grammar and syntax. This device, if it exists, would constitute the evolutionary development that set us apart from the apes. ${ }^{11}$

It may be interesting to note here how these functions were discovered. Sometimes we appreciate the function and usefulness of a structure by its absence; that is, after it is somehow damaged. This is actually how the function of the various parts of the brain, including the frontal lobes, was initially delineated; by experimentally ablating each part (in animals, of course), and reassessing the resulting loss of function. In humans, early neurologists would similarly study the effects of strokes, accidents, destructive tumours, and other processes that caused an ablation of a part of the brain. As Gazzaniga (2008) states, 'focal brain lesions produced discrete and specific deficits in patients. If a specific part of the brain is damaged, there are specific disorders of language, thought, [perception, attention, and so on]. And nowhere were such phenomena more dramatic than in split-brain patients, proving that the left side of the brain is specialized for one set of capacities and the other side for another kind.' We will return to the notion of brain (hemispheric) specialization again later on. An industrial accident, which occurred in the nineteenth century, gave us the first clues about the function of the frontal lobes. The case is briefly described below.

Phineas Gage was an energetic, responsible young American man with initiative at his work that commanded the respect of his superiors. He was the foreman of a railway construction crew. Unfortunately he was involved in a freak work-related accident when he was using a steel rod to ram a charge of blasting powder into a hole that was carved into a rocky surface. The charge exploded unexpectedly and sent the rod into his cheek, through his frontal lobe, and out of the top of his skull. The accident had destroyed a good part of his frontal lobes and he came close to dying. He did survive however and appeared to have sustained no long term consequences initially. But with time it became obvious that he was not the same person as before the accident. He began acting irresponsibly, erratically, with disrespect for others, and, at times, recklessly. His personality had made a complete turnaround as a result of the damage he had suffered in his frontal lobes (Damasio 1994). In fact, there is

11 This 'device' would not be an anatomic location in the brain but a functional network of neurons organized accordingly, following the activation and inactivation of genes, in order to bring about the acquisition of speech and language. 
evidence that lesions anywhere in the frontal lobes of the brain will cause behavioural symptoms as well as personality changes, especially executive dysfunction, meaning affectation of the ability to make decisions, reason, and plan appropriate actions (Tullberg et al. 2004). The importance of the frontal lobes for our humanness is thus obvious. Suffice it to mention that the speech centre is also located in the frontal lobes; this is an important component of language, perhaps the single most important characteristic that made us human and enabled the development of culture.

\section{V.}

Pre-humans (including primates) used tools in their everyday activities. As we saw above, evolution selected out those brains that used tools more efficiently according to the mechanisms described earlier. Gradually, larger brains appeared that manufactured more complex tools. They also, through mutations, produced language and abstract ideas that were advantageous for survival; and, subsequently, culture. ${ }^{12}$ The English anthropologist Edward Burnett Tylor (1889) wrote that 'culture is that complex whole which includes knowledge, belief, art, morals, law, custom, and any other capabilities and habits acquired by man as a member of a society', whereas, more recently, Ashley Montague (1968) defined culture as follows; 'With the creation and usage of organized systems of symbols man created a new dimension of experience ... we call culture. Culture is man-made. It is the environment which man creates in order the better to control as much of the environment as he desires.' Domestication of animals and plants through culture, helped develop a surplus, a sedentary life, and the rise of specialists (McClary 1975). Through culture came the development of such things as social stratification, roles and division of labour, and expectations about appropriate behaviour (social norms and codes). In addition, the limits of normal and abnormal behaviour as they related to and enhanced the survival chances of the group at large in specific environments were set. These could be diametrically opposite in different environments but perfectly appropriate for their own needs and circumstances; to abandon ailing grandma in a hospital or nursing home in Western cultures is an example of deplorable and despicable behaviour; to abandon ailing grandma in an Eskimo igloo is an example of expected, accepted, and

12 Culture in this context is thought of as one of the most, if not the key, genetic determinants of what constitutes humanness. 
appropriate behaviour when her small kinship group will need to get on in search of food in harsh environmental conditions, and this is typically the behaviour that is traditionally seen.

An evolutionary legacy we have retained from our biological ancestors is the need to form social hierarchies and orders. To have them functioning in an orderly way, a leader or group of leaders (elders, senators, parliamentarians, and what have you) are found on top. Such a development became necessary in order to manage the increasingly more complex cultural systems that arose around the globe. Evolution would not have left the selection of leaders to chance, but it would have developed such social behaviours, so that the most appropriate member of any given group would rise to the top. That leader would consequently enhance the group's survival.

We now return to our initial question; has evolution produced a species that is genetically programmed to take on its destiny on an individual basis, or as a multitude that is pre-destined to follow leaders? And if the latter is true, which characteristics in a leader are those that the crowd has been genetically programmed to be attracted to? An individual alone cannot of course make significant strides in progress. He must clearly act within a social group in order to have an impact with his contributions. ${ }^{13}$ Aristotle wrote that man is a social animal. As the first biologist, he was echoing future concepts about genetic determinants of behaviour including the formation of social groups. Any innovation must be adopted and accepted by, as well as get incorporated into a social context, in order to affect behaviour in some way. Ridley (2003) wrote that 'A solitary human mind cannot secrete culture'. Therefore, interplay takes place between the group and the individual. The question to answer is which of the two in this relationship assumes the leading role and which follows. As Samuel Johnson (Bloom 1986) observed in the eighteenth century, 'No two people can be half an hour together, but one shall acquire an evident superiority over the other'. Moreover, another issue to tackle would be whether the same process holds for all group-to-individual relationships or whether different circumstances create variable arrangements.

In every historically important moment of human affairs, there appear to have appeared great individuals that led the way. As the old English expression goes, 'Cometh the hour, cometh the man' the implication is

13 Cultural traits can also diffuse across cultures and effect changes in the receiving group. Again, this is accomplished between social contexts and has the same effects as those new traits that are introduced into a group by an individual within. 
that each circumstance requires its particular leader. From Abraham to Caesar, from Christ to Muhammad, from Constantine to Washington, from Stalin to Hitler, all these individuals have led their 'people' into destinies that they had not foreseen. The list is endless. Could there be a common underlying factor that determines the process of their advance, and if there is, could it be biologically explained? Birds for example that submit to a pecking order are so programmed biologically; and so are the ones doing the pecking (the leaders). Some trait puts both the pecker and the ones being pecked on notice about their respective place in the system. Wild herds are also known to form hierarchies that, once they get established, are adhered to until another animal in the herd (which itself usually rates high on the hierarchy), challenges the order. Primates are no exception to this phenomenon. The trait, I will argue subsequently, is a form of mental state (illness if you will), known as paranoia; it characterizes many psychiatric and psychological conditions, yet it confers leadership qualities on its bearers by producing a certain kind of personality that has a natural propensity to lead. Mental illness, like many other kinds of illnesses, has its biological substrate and as such, is subject to the laws of genetics and inheritance. In that respect I will attempt to convince my readers that, as William $\mathrm{H}$. Hampton and Virginia Schroeder Burnham (1990) claimed, 'Paranoia has promoted and yet restricted our evolution in the development of the family, communities, and nations. It was part of the process by which human beings progressed from a primitive to a cultured civilized state. Paranoia is also responsible for the evolution of politics, religions, war, peace, science and technology.'

Paranoia was once considered to be a characteristic of only mental illness; however, recently conducted studies have been revealing that paranoia may be much more common than previously thought; it may affect up to one in three people in the general public and may also be on the rise (most likely as an evolutionary triggered adaptive mechanism), in recent times, given the rise of world terrorism, the fall of communism, the fall of capitalism, and the global disintegration of values. Daniel Freeman et al. (2008) conducted an experiment in which he simulated the situation that exists in the London Underground and discovered that up to 40 per cent of his volunteer study group harboured at least one unfounded paranoid thought towards neutral others. As he puts it, 'Paranoid thoughts are often triggered by ambiguous events such as people looking in one's direction or hearing laughter in a room.' As an explanation he states that 'at the heart of all social interactions is a vital judgement whether to trust or mistrust, but it is a judgment that is error-prone. We are more likely to make paranoid errors if we are 
anxious, ruminate, and have had bad experiences from others'. Our time, the New Common Era, is rife with anxiety and misgivings. Such a condition likely triggers an evolutionary-determined gene-activating process that puts individuals into hyper-alert states, in order to maximize their defences and chances for survival. This would explain the unfortunate event of the shooting by police of an innocent man in the London Underground shortly after the 7 July 2005 bombings that shocked the British nation. I will not deal further with the mechanistic process of human evolution or its differentiation from other primates, except when such a discussion would be illustrative of my primary thesis regarding the relationship of language, mental illness and leadership. Recently published extensive treatises have adequately expounded on the topic (Leakey and Lewin 1992, Ridley 2003, Gazzaniga 2008).

Moreover, I will take it for granted that most political leaders have been on the odd end of the personality spectrum, as this fact is well accepted by most people without question. This also applies to leaders in general. Recently, I was following a conversation regarding the late Prime Minister of Greece, Andreas Papandreou, and his late-life escapades. ${ }^{14}$ What an eye-opener it was for me to find out that he was chronically on treatment with lithium, a drug used to curtail the exacerbations of manic depressive (bipolar) illness. ${ }^{15}$ This individual was holding his country's fate in his hands for decades. Post (2003) uses the term 'terminal machismo' in discussing Papandreou's personality - a term that could be applied to the rest of the bunch. Alexander, Ceasar, the Roman Emperor Constantine, Pope Clement VII, Napoleon Bonaparte, Vladimir Lenin, Adolf Hitler, Winston Churchill, Josef Stalin, Saddam Hussein and Osama bin Laden, to name but a few leaders readily recognized by everyone, need no introduction when their personality peculiarities are under discussion. I will not devote much space to character or biographical descriptions of individual leaders, political or otherwise, except briefly to illustrate my claims. Many books have been written on illustrious historical as well as current leaders. The interested reader may find a plethora of them through a brief perusal of any bookstore or the internet. I will mention names as the need arises to make my points clear.

The basic tenet of the book is that leaders are qualitatively different from followers; that these differences are biologically (genetically)

14 In his 70s, he divorced his wife of many years and married an airline stewardess.

15 Bipolar illness is discussed fully in Chapter 8. 
determined; that an important difference lies in their use of language; that language itself is a uniquely developed human characteristic which is evolutionarily associated with the appearance of psychiatric disorders; and that we probably possess the capacity to activate certain genes at times of crisis which 'allow' us to appoint paranoid leaders in charge, because they appear to possess the 'right stuff' to see us through our troubles. It is reasonable to assume, then, that some biologically determined traits that have survived across species that live in teams, including man, enhance their structuring and stratification in an orderly and systematic way. Humans appear to have retained these traits as well, and Aristotle is proved correct in his ancient pronouncement (see above).

We may now bring biology and sociology together to help explain this phenomenon. What makes some humans leaders, others followers, and why our leaders' personalities fall outside the average of observable behaviours, will be discussed in the rest of this book. 